\title{
Enhanced Lung Maturation in Cocaine-Exposed Rabbit Fetuses
}

\author{
ZEEV N. KAIN, ${ }^{1}$ MALA R. CHINOY, ${ }^{2}$ MARIA T. ANTONIO-SANTIAGO, ${ }^{3}$ \\ ROBERTO N. MARCHITELLI, AND EMILE M. SCARPELLI ${ }^{4}$ \\ Long Island Jewish Medical Center for Albert Einstein College of Medicine, New Hyde Park, New York 11042
}

\begin{abstract}
Because of cocaine's possible effect on the incidence of respiratory distress syndrome in offspring of cocaine-addicted mothers, we have studied the effects of maternal exposure to cocaine on the functional anatomy of fetal rabbit lungs. Pregnant dams were injected s.c. daily with either cocaine $(18 \mathrm{mg} / \mathrm{kg})$ or an equal volume of $0.9 \%$ $\mathrm{NaCl}$ at 24, 25, and 26 d gestation. Cocaine metabolites were confirmed both in urine of treated dams and in fetal amniotic fluid. Serum cortisol levels were higher in treated dams than in controls. Fetuses were delivered through hysterotomy at $27 \mathrm{~d}$. Tracheas were cannulated and a volume-pressure diagram was obtained during initial lung inflation-deflation. Volume was measured for $2 \mathrm{~min}$ at each pressure (P) increment of $5 \mathrm{~cm} \mathrm{H}_{2} \mathrm{O}$. Body weights and dry lung weights were comparable between the two groups. In contrast, cocaine-exposed lungs differed from controls as follows: 1$)$ wet lung weights were lower $(0.79$ versus $0.89 \mathrm{~g}, p<0.02) ; 2$ ) opening pressure was lower (P25 versus $\mathrm{P35}) ; 3)$ volume $(\mathrm{mL} / \mathrm{kg})$ was higher in treated animals at each pressure step $(p<0.05) ; 4)$ end-deflation volume at $\mathrm{P0}$ was higher $(30.4$ versus $0.8 \mathrm{~mL} / \mathrm{kg}, p<$ 0.001 ); and 5) bubbles released from saccules by micropuncture, which were stable by Pattle's criteria, had estimated surface tension near zero (controls produced no stable bubbles). Light micrographs of cocaine-exposed fetuses revealed more secondary septa and thinner septal walls than controls. We conclude that fetal exposure to cocaine results in increased lung distensibility and stability, induction of low surface tension, and morphologic transformations, each of which is consistent with accelerated lung maturation. The cortisol surge suggests a steroid-mediated mechanism for this effect. (Pediatr Res 29: 534-537, 1991)
\end{abstract}

\section{Abbreviations}

VP, volume-pressure

In the past decade, cocaine abuse in the United States has reached epidemic proportions. It is estimated that about 5 million Americans use cocaine regularly (1). The documented increase in cocaine abuse by the general population parallels increased usage by pregnant females (2). Maternal cocaine abuse has been

Received April 11, 1990; accepted January 18, 1991

Correspondence and reprint requests: Dr. Zeev Kain, Yale University, Department of Anesthesiology, 333 Cedar Street, P.O. Box 333, New Haven, CT 06510.

Now at Department of Anesthesiology, Yale University School of Medicine, New Haven, CT. $\mathrm{PA}$

Now at Department of Physiology, University of Pennsylvania, Philadelphia,

${ }^{3}$ Now at the Department of Pediatrics, University of Medicine and Dentistry of New Jersey, Newark, NJ.

${ }^{4}$ Now at the Perinatology Center of the New York Hospital-Cornell University Medical Center, New York, NY. associated with intrauterine growth retardation (3), low birth weight infants $(3,4)$, and increased risk of CNS complications $(2,3,5)$

A pharmacologic effect of cocaine is prevention of norepinephrine reuptake from synaptic spaces. It is also reported that cocaine mediates release of catecholamines from the adrenal medulla (6) and stimulates the pituitary-adrenal axis, resulting in an elevation of plasma corticosterone (7). Although catecholamines and corticosteroids enhance lung maturation, preliminary studies on the incidence of respiratory distress syndrome in premature infants born to cocaine-abusing mothers are conflicting $(8,9)$. Lung growth and maturation are affected by multiple variables that cannot be isolated in a clinical study. We therefore decided to investigate the effect of intrauterine cocaine exposure on fetal lung maturation in an animal model.

\section{MATERIALS AND METHODS}

The animal experiments described in this paper were performed with the highest standards of humane care.

Five pregnant New Zealand White rabbits (Camm Research, Wayne, NJ) were injected with cocaine hydrochloride U.S.P. (Mallinckrodt, Paris, KY) at a dose of $18 \mathrm{mg} / \mathrm{kg} / \mathrm{d}$ s.c. on $\mathrm{d} 24$, 25 , and 26 of gestation (77 to $84 \%$ of total gestational period). Simultaneously, a control group of five pregnant dams was injected with an equal volume of $0.9 \% \mathrm{NaCl}$. Urine was sampled daily between 12 and $24 \mathrm{~h}$ after each injection. Benzoylecgonine, the primary cocaine metabolite, was measured in the urine of pregnant dams and in fetal amniotic fluid at the time of delivery by Fluorescence Polarization Immunoassay using a TDX analyzer (Abbott Laboratories, N. Chicago, IL). This assay is sensitive to $50 \mathrm{ng} / \mathrm{mL}$ benzoylecgonine; levels $\geq 50 \mathrm{ng} / \mathrm{mL}$ are considered definitive evidence of cocaine intake.

At $27 \mathrm{~d}$ of gestation, the dams were anesthetized with $30 \mathrm{mg} /$ $\mathrm{kg}$ of pentobarbital i.v. and maternal serum was obtained for cortisol analysis using a RIA kit (Amersham, Arlington Heights, IL). Fetuses were delivered through a hysterotomy, weighed, and handled as previously described (10). Briefly, the neck was ligated to prevent air entry into lungs, and a polyvinyl catheter was inserted into the trachea through a subglottic incision. Chest wall was left intact.

$V P$ diagrams. The tracheal cannula was attached to a $5.0-\mathrm{mL}$ glass pipette that was connected to a $2.4-\mathrm{L}$ glass cylinder. Air pressure to the lungs was increased in $5-\mathrm{cm}_{2} \mathrm{O}$ increments by raising the water level in the cylinder, and volume change was recorded from the meniscus in the pipette after 2 min at each setting. Maximum pressure was $40 \mathrm{~cm} \mathrm{H}_{2} \mathrm{O}$ (P40). This was followed by lowering the pressure in the cylinder in 2-min, $5-\mathrm{cm}$ $\mathrm{H}_{2} \mathrm{O}$ steps while recording volume change. Volume was normalized to body weight in $\mathrm{kg}$ and plotted on pressure. Where leaks developed, lungs were discarded and data excluded. After obtaining VP measurements, lungs were weighed (wet weight), ovendried at $80^{\circ} \mathrm{C}$ for at least $48 \mathrm{~h}$, and reweighed (dry weight).

Bubble stability. At end-deflation (P0), intrasaccular bubbles 
were released by micropuncture into aerated normal saline solution (11). Bubble diameter was determined at 5 and $30 \mathrm{~min}$ through a Zeiss light microscope. Bubble stability and surface tension were assessed from these measurements according to the criteria of Pattle (12).

Histology. Intact lungs from cocaine- and saline-exposed fetuses were fixed in $10 \%$ buffered formaldehyde at P0 immediately after VP measurements. Paraffin sections of $6 \mu \mathrm{m}$ were stained with hematoxylin-eosin and assessed for lung maturation. Thinning of alveolar septa, formation of secondary septa, and increase of intraalveolar airspace were taken as parameters of maturation.

Statistics. The $t$ test was used to determine the significance of differences between group means. Significance was accepted at $p$ $<0.05$.

\section{RESULTS}

General differences, not explained by our data, between the cocaine-treated and control dams included reduced spontaneous activity, apparently engorged and larger placentas, and 10\% incidence (four of 38 ) of gross fetal malformations in the treated group.

At a cocaine dose of $18 \mathrm{mg} / \mathrm{kg} / \mathrm{d}$, benzoylecgonine levels were higher than $50 \mathrm{ng} / \mathrm{mL}$ both in the urine of pregnant dams and in fetal amniotic fluid. Serum cortisol levels $(\mu \mathrm{g} / \mathrm{dL})$ were higher in cocaine-treated gravid dams than in controls $(7.6 \pm 2$ versus $1.3 \pm 0.4, p<0.01$ )

The effects of intrauterine cocaine exposure on fetal body and lung weight are shown in Table 1 . Body weights and dry lung weights of the control and cocaine groups were not different. In contrast, wet lung weights were lower in the cocaine-exposed group $(0.79 \pm 0.03 \mathrm{~g})$ compared to controls $(0.89 \pm 0.03 \mathrm{~g})$.

The VP diagrams of the two groups were different during both inflation and deflation (Fig. 1).

Inflation. 1) Opening pressure, i.e. the pressure during inflation above which fetal saccules are recruited and below which only airways are inflated, was lower in the cocaine group, consistently P25, than in the control group, consistently P35.2) Distensibility of the conducting airways was higher in the cocaine group: presaccular recruitment volume was $14 \pm 1.2 \mathrm{~mL} / \mathrm{kg}$ at $\mathrm{P} 25$ for the cocaine fetuses and $11.9 \pm 0.83$ at P35 for control; therefore, airway distensibility was $0.56 \pm 0.2$ and $0.34 \pm 0.1 \mathrm{~mL} / \mathrm{kg} / \mathrm{cm}$ $\mathrm{H}_{2} \mathrm{O}$, respectively $\left.(p<0.01) .3\right)$ Saccular distensibility as indicated by volume change from P35 to P40 (the only region in which saccules were inflated in the control group) was also higher in the cocaine group: calculated distensibility was $5.3 \pm 1.7 \mathrm{~mL} /$ $\mathrm{kg} / \mathrm{cm} \mathrm{H}_{2} \mathrm{O}$ for the cocaine group and $3.5 \pm 1 \mathrm{~mL} / \mathrm{kg} / \mathrm{cm} \mathrm{H}_{2} \mathrm{O}$ for control $(p<0.01)$.

Deflation. l) A higher volume was retained in cocaine lungs throughout each phase of deflation, including early deflation, where volume increased as pressure was lowered ["negative compliance," i.e. constant or increased volume as pressure is lowered

Table 1. Comparison of control and cocaine-exposed fetuses*

\begin{tabular}{lcc} 
& Control & Cocaine \\
\hline No. of litters & 5 & 5 \\
No. of fetuses & 37 & 34 \\
BW (g) & $29.3 \pm 0.7$ & $30.5 \pm 0.6$ \\
Lung wet wt $(\mathrm{g})$ & $0.89 \pm 0.03$ & $0.79 \pm 0.03 \dagger$ \\
Lung dry wt $(\mathrm{g})$ & $0.097 \pm 0.02$ & $0.091 \pm 0.03$ \\
(Wet wt/BW) $\times 10^{3}$ & $29.8 \pm 0.6$ & $25.3 \pm 0.8 \dagger$ \\
(Dry wt/BW) $\times 10^{3}$ & $3.28 \pm 0.3$ & $2.94 \pm 0.4$ \\
Wet/dry wt & 8.92 & 8.65 \\
VP curves $(\mathrm{mL} / \mathrm{kg})$ & & \\
P40 & $29 \pm 1.6$ & $73 \pm 2.5 \dagger$ \\
P0 & $0.8 \pm 0.2$ & $30 \pm 3.2 \dagger$ \\
\hline
\end{tabular}

$*$ Values are mean \pm SEM. BW, body wt; $\mathrm{P}$, pressure. $+p<0.05$.

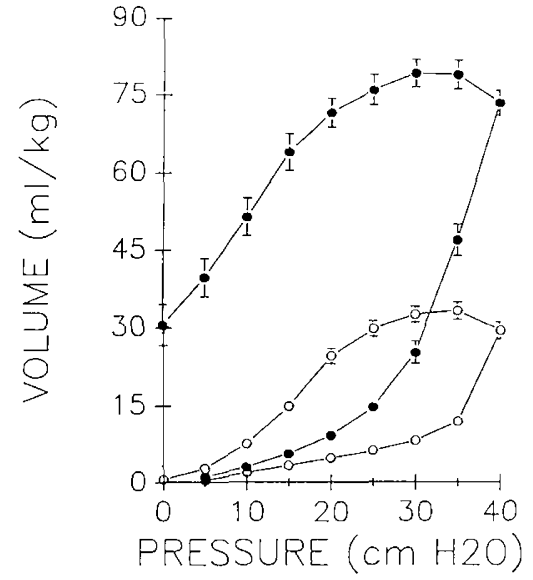

Fig. 1. VP diagrams of control (O) and cocaine-exposed (-) fetal lungs during first inflation-deflation with air (see text for explanation).

(13)]; mid-deflation, P30 to P10, where volume fell rapidly as pressure was lowered; and end-deflation, P10 to P0, where volume change was less with each pressure step (see Fig. 1). 2) At end-deflation, P0, volume in the cocaine group was $38 \%$ (30 $\mathrm{mL} / \mathrm{kg}$ ) of maximum volume, whereas end-deflation volume of the control group was $1.6 \%(0.8 \mathrm{~mL} / \mathrm{kg})$ of maximal volume (Table 1).

There was no significant change from 5 to $30 \mathrm{~min}$ in the diameter of bubbles of cocaine lungs that were transferred from saccules to air-equilibrated normal saline solution. Using the criteria of Pattle (12), the stability ratio of these bubbles was 1.0 and the estimated surface tension of their films was virtually zero. In contrast, bubbles from the control group ruptured within $15 \mathrm{~min}$ after being released in the normal saline solution.

Light micrographs are shown in Figures 2 and 3. The markedly greater aeration of cocaine-exposed lung at end-deflation, $\mathrm{P} 0$, is clear when compared with control lungs in which little air was retained (Fig. $2 A$ and $B$ ). In addition, the rather uniform distribution of retained air in the cocaine lungs was seen consistently. The differences in septal development, which signify enhanced maturation, are apparent: after exposure to cocaine, the fetal septa are thinner and more secondary septa have been formed. In addition, under high magnification (Fig. $3 A$ and $B$ ), decreased cellularity of the septa is striking. Decreased cellularity in association with new septa formation is the basis for the air space enlargement and convolution that mark enhanced maturation.

\section{DISCUSSION}

Results of clinical studies aimed at establishing the association of cocaine addiction with the incidence of respiratory distress syndrome are conflicting $(8,9)$.

We elected to study this problem in a well-defined setting in which dosage, duration of exposure, and fetal gestational age at exposure were controlled. In addition, many of the problems that influence clinical studies such as maternal smoking, infection, and multiple drug abuse were eliminated.

There is no precedent literature on cocaine dosimetry in rabbits. Therefore, we did preliminary experiments in pregnant and nonpregnant rabbits to determine the daily dose required to produce levels of benzoylecgonine greater than $50 \mathrm{ng} / \mathrm{mL}$, both in urine and in amniotic fluid. Benzoylecgonine is the specific metabolite of cocaine, and the level chosen is consistent with generally accepted criteria for cocaine exposure. The materials tested, amniotic fluid and urine, indicated exposure of both dams and fetuses. The preliminary studies on urinary excretion of the metabolite had shown that definitive levels were reached within $12 \mathrm{~h}$ and sustained for the entire period.

In our study, exposure was limited to d 24 through 26 of gestation, which mark the end of the canalicular stage of devel- 


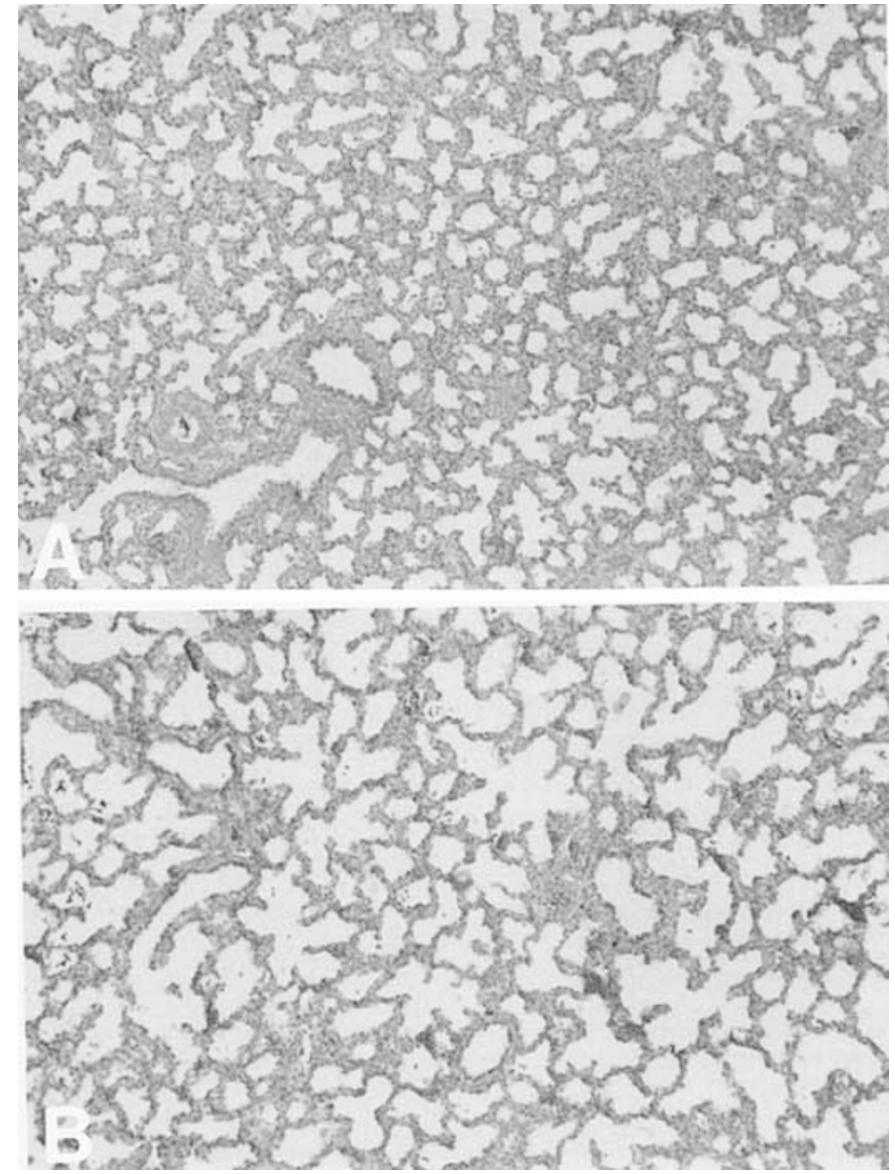

Fig, 2. Fetal lungs at end-deflation, P0. (A) Control lungs show relatively little air retention and uneven distribution of air. In contrast, lungs from cocaine-exposed fetuses (B) are better and more uniformly aerated. $\times 113$.

opment, the stage in which type 2 cell differentiation and acceleration of surfactant synthesis has, in general, not yet begun. Thus, an effect on lung maturation might be defined more readily. Fetal lungs were studied at $27 \mathrm{~d}$, which marks the beginning of the saccular stage of development wherein pulmonary function retains immature characteristics.

It is clear from our studies that exposure of the fetus to cocaine resulted in acceleration of lung maturation. First, the distribution and retention of air was visibly and consistently increased with cocaine exposure. At the same time, lung distensibility increased. These characteristics of Iung mechanics are universally accepted (14) as hallmarks of maturation. Second, the cocaine-exposed lungs formed stable bubbles of zero surface tension during inflation-deflation, which indicates that surfactant production had been stimulated. Indeed, using the criteria of Pattle (12), it can be concluded that the amount of surfactant in the cocaineexposed lungs was sufficient to reduce surface tension to virtually zero. In contrast, the control lungs did not produce stable bubbles, indicating that surfactant production had not matured, as is to be expected in normal $27-\mathrm{d}$ rabbit fetuses. Previous studies have certified that the capacity to form stable bubbles is related directly to surfactant production during maturation of the fetal lung (15). The functional consequences of enhanced surfactant production are well known (16). They are particularly relevant to bubble production in situ, which enhances air retention both during deflation and at end-deflation $(10,11,15)$. Third, the morphologic changes associated with cocaine exposure, i.e. septal thinning, reduced cellularity, and formation of secondary septa, are also consistent with accelerated maturation (17). The functional significance of the morphologic changes may be suggested

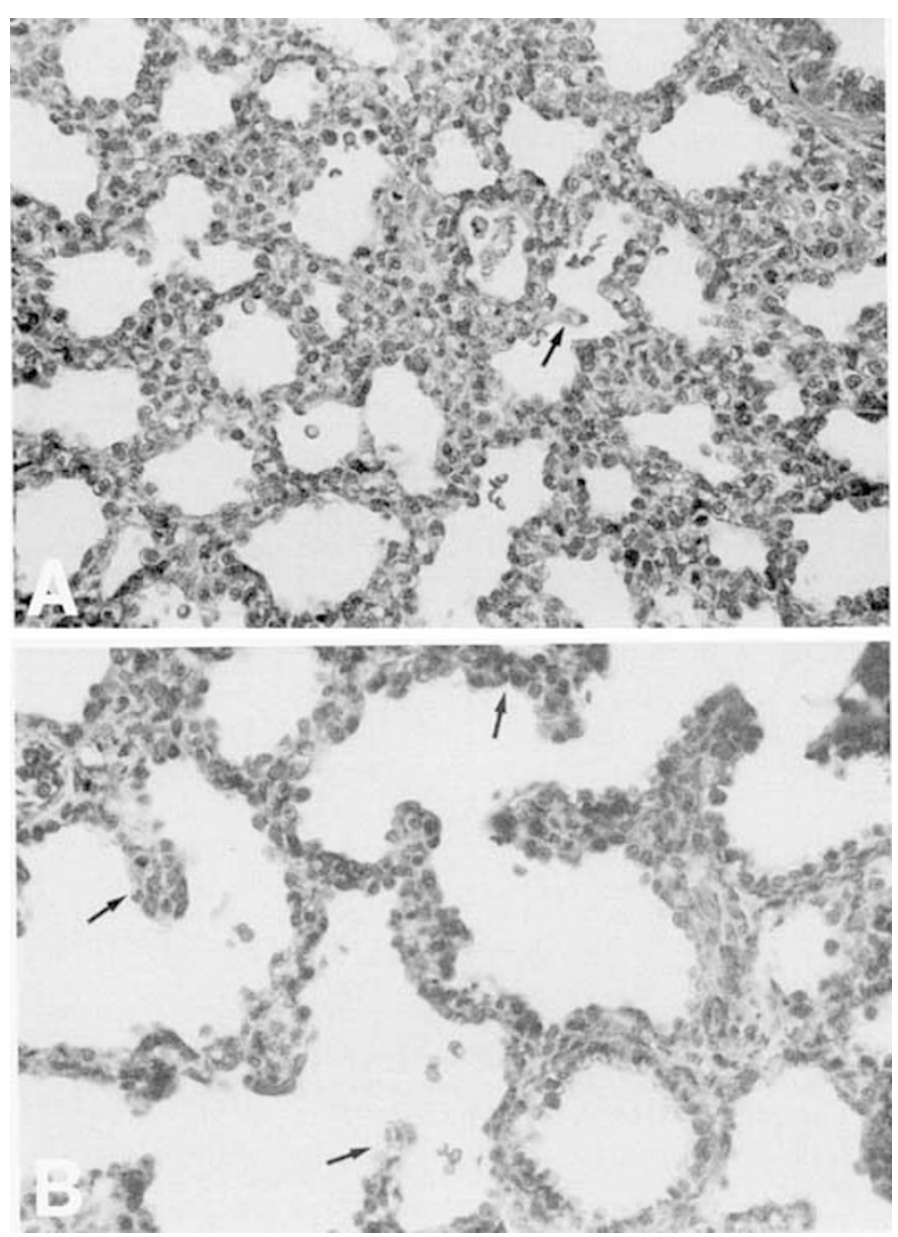

Fig. 3. Fetal lungs at end-deflation, P0. Higher magnification shows thinner septa and more prominent secondary septa (arrows) in cocaineexposed (B) as compared with control (A) lungs. Decreased cellularity of the septa is striking. $\times 450$.

(17): septal thinning would be expected to reduce (as compared with control lungs) the pressure required for aeration, and the capacity of the parenchyma to contain air would expectedly increase as a consequence of the process of septation and increased alveolarization. Acceleration of connective tissue development at the same time, particularly acceleration of elastin production, would yield lungs that are more distensible (17), as shown in Figure 1.

The mechanisms for cocaine-induced lung maturation may be inferred from studies on the pharmacologic effects of the drug. Intraperitoneal administration of cocaine to rats stimulates release of pituitary adrenocorticotropic hormone and endogenous catecholamines from the adrenal medulla and produces significant elevation of plasma corticosterone (7). Thus, cocaine may affect fetal lung maturation by both a glucocorticoid and catecholamine mechanism.

The influence of corticosteroids on fetal lung maturation has been studied for almost two decades. Glucocorticoids induce cytodifferentiation of type 2 cells and stimulate both synthesis and release of surfactant into the alveolus. Other morphologic changes associated with glucocorticoid treatment include flattening of epithelial cells, thinning of mesenchyme, reduced interstitial volume and an increase in total air-space volume (18). The mechanisms by which glucocorticoids may affect interstitial morphogenesis may be related to inhibition of fibroblast proliferation and stimulation of elastogenesis by these cells (18). The subsequent condensation and alteration of interstitial matrix could promote alveolarization.

$\beta$-Adrenergic drugs are known to increase the synthesis and 
possibly the secretion of surfactant in the fetus $(19,20)$. The fact that infants of cocaine-abusing mothers have elevated circulating norepinephrine is consistent with the additional possibility that acceleration of lung maturation among cocaine-exposed fetuses is induced by catecholamines (21). The particular effect of catecholamines on pulmonary morphogenesis is not as well understood as it is for corticosteroids.

Studies by Kikkawa et al. (22) also suggest that thyroxine is capable of accelerating fetal rabbit lung maturation. Because catecholamines are known to stimulate thyroid hormone synthesis and release, and may play a role in the regulation of thyroid hormone secretion under certain circumstances, this could be a pathway for the catecholamine effect (23).

Chasnoff et al. (3) recently reported an association between maternal cocaine abuse throughout pregnancy and fetal intrauterine growth retardation. More et al. (24) have suggested on the basis of studies in pregnant ewes that decreased intrauterine fetal growth results from intermittent interruption of placental blood flow associated with maternal cocaine abuse. In contrast, we found that birth weights of both control and cocaine fetuses were comparable to reported weights of normal 27-d rabbit fetuses (14). This could be because of the short-term exposure in our studies. Nevertheless, the lung wet weights of the cocaineexposed fetuses were lower than expected for the gestational age, a finding that is consistent with the effects of short-term exposure to catecholamines (19). The effect of steroid exposure on lung weight is unclear. Some studies have shown no change, while others have demonstrated decreased lung weight (25-28).

We used the levels of cocaine metabolites in fetal amniotic fluid to confirm intrauterine exposure to the drug. To date, the conventional method to confirm cocaine exposure during pregnancy is a urinary assay for drug metabolites in the newborn infant. This may impose a delay of several hours before an adequate urine collection is obtained. Although this study does not certify the reliability of amniotic fluid testing, we do suggest that the amniotic fluid assay for cocaine metabolites could provide an early and reliable indication of fetal exposure. This matter requires further study.

\section{REFERENCES}

1. Abelson HI, Miller JD 1985 A decade of trends in cocaine use in the household population. Natl Inst Drug Abuse Res Monogr Ser 61:35

2. Chasnoff IJ, Burns WJ, Schnoll SH, Burns KA 1985 Cocaine use in pregnancy. N Engl J Med 313:666-669

3. Chasnoff IJ, Griffith DR, MacGregor D, Dinkes K, Burns KA 1989 Temporal patterns of cocaine use in pregnancy. JAMA 261:1741-1744

4. Zuckerman B, Frank DA, Hingson R, Amaro H, Levenson SM, Kayne H, Parker S, Vinci R, Aboagye K, Fried LE, Timperi A, Bauchner H 1989
Effects of maternal marijuana and cocaine use on fetal growth. $N$ Engl $J$ Med 320:762-768

5. Doberczak TM, Shanzer S, Senie RT, Kandall SR 1988 Neonatal neurologic and electroencephalographic effects of intrauterine cocaine exposure. $J$ Pediatr 113:354-358

6. Chieuh CC, Kopin IJ 1978 Centrally mediated release by cocaine of endogenous epinephrine and norepinephrine from the sympathoadrenal medullary system of unanesthetized rats. J Pharmacol Exp Ther 205:148-154

7. Moldow RL, Fischman AJ 1987 Cocaine induced secretion of ACTH, betaendorphine, and corticosterone. Peptides 8:819-822

8. Wu S, Raval D, Anyebuno M, Wieus A. Pildes RS 1989 Does cocaine affect pulmonary status of LBW infants. Pediatr Res 25:236A(abstr)

9. Maynard EC, Dreyer SA. Oh W 1989 Prenatal cocaine exposure and hyaline membrane disease (HMD). Pediatr Res 25:223A(abstr)

10. Scarpelli EM, Kumar A, Doyle C, Clutario C 1981 Functional anatomy and volume-pressure characteristics of immature lung. Respir Physiol 45:25-41

11. Scarpelli EM, Clutario BC, Mautone AJ, Baum J 1984 Intrasaccular bubbles of near-zero surface tension stabilize neonatal lung. Pflugers Arch 401:287292

12. Pattle RE 1958 Properties, function and origin of the alveolar lining layer, Proc R Soc Lond [Biol] 148:217

13. Mead J 1961 Mechanical properties of lungs. Physiol Rev 41:281-330

14. Kotas RV, Avery ME 1971 Accelerated appearance of pulmonary surfactant in the fetal rabbit. J Appl Physiol 30:358-361

15. Scarpelli EM 1978 Intrapulmonary foam at birth: an adaptational phenomenon. Pediatr Res 12:1070

16. Scarpelli EM 1988 Surfactants and the Lining of the Lung. Johns Hopkins Press, Baltimore, pp 1-121

17. Brody JS, Thurlbeck WM 1986 The respiratory system. In: Fishman AP (ed) Handbook of Physiology. American Physiological Society, Bethesda, MD, pp 356-386

18. Ballard PL 1986 Hormones and Lung Maturation. Springer-Verlag, Berlin, pp 24-129

19. Enhorning G, Chamberlain D, Robertson B 1977 Isoxuprine-induced release of pulmonary surfactant in the rabbit fetus. Am J Obstet Gynecol 129:197202

20. Wyszogrodski I, Taeusch HW, Avery ME 1974 Isoxuprine-induced alterations of pulmonary pressure-volume relationships in premature rabbits. Am J Obstet Gynecol 119:1107-1111

21. Ward SLD Bautisda DB, Buckley S, Schuetz, S, Wachsman L, Bcan X, Warburton D 1988 Circulating catecholamine and adrenoreceptors in infants of cocaine abusing mothers. Pediatr Res 23:74A(abstr)

22. Kikkawa BWY, Orzalesi MM, Motoyama EK, Kaibara MK, Zigas CJ, Cook CD 1973 The effect of thyroxine on the maturation of fetal rabbit lungs. Biol Neonate 22:161-168

23. Landsberg L, Young JB 1987 Catecholamines and the sympathoadrenal system. In: Green WL (ed) The Thyroid. Elsevier, New York, pp 910-911

24. More TR, Sorg J, Miller L 1986 Hemodynamic effects of intravenous cocaine on the pregnant ewe and fetus. Am J Obstet Gynecol 155:883-888

25. Motoyama EK, Orzaleski MM, Kikkawa Y, Kaibara M, Zigas CJ, Cook CD 1971 Effect of cortisol on the maturation of fetal rabbit lungs. Pediatrics 48:547-554

26. Beck JC, Mitzner W, Johnson JWC, Hutchins GM, Foidart JM, London WT Palmer AE, Scott R 1981 Betamethasone and the rhesus fetus: effect on lung morphometry and connective tissue. Pediatr Res 15:235-240

27. Adamson IYR, King GM 1988 Postnatal development of rat lung following retarded fetal lung growth. Pediatr Pulmonol 4:230-236

28. Mitzner W, Johnson JWC, Beck J, London W, Sly D 1982 Influcnce of betamethasone of the development of mechanical propertics in the fetal rhesus monkey lung. Am Rev Respir Dis 125:233-238 